\title{
Orbito cerebral complications of poly sinusitis
}

\author{
Soulé Alamou ${ }^{1}$, Lisette YehouessI ${ }^{1}$, Chakiratou Abouki ${ }^{1}$, Olivier Biaou ${ }^{2},{\text { Hermann } \text { Ngoufo }^{1} \text {, Wassi Adjibabi }}^{3}$ and Claudia Doutetien $^{1}$ \\ ${ }^{1}$ Ophthalmology Department, University Hospital HKM of Cotonou, PoBox 386 Cotonou, Benin \\ ${ }^{2}$ Imagery Department, University Hospital HKM of Cotonou, Benin \\ ${ }^{3}$ Otorhinolaryngology, Cervico-Facial Surgery Department, University Hospital HKM of Cotonou, Benin
}

\begin{abstract}
Intra -orbital and brain abscesses are rare but severe complications of poly sinusitis. These attacks are often unilateral. We reported a case of bilateral intra-ocular damage of a 65-year-old male with a history of purulent rhinitis lasting for three months and who presented a significant chemosis and painful axile breathless in both eyes associated with an infectious syndrome. The orbito frontal brain's CT scan noted a pansinusitis complicated bilateral intra-orbital abscess and empyema brain. The triple antibiotic probabilistic led to transient improvement of symptoms, but hyperthermia persisted for three weeks. The interest of this case lies in the scarcity of bilaterality of orbital complications associated with cerebral empyema of sinus origin, the importance of CT in the accurate diagnosis of the disease and therapeutic difficulties.
\end{abstract}

\section{Introduction}

The intraorbital abscess is defined as a collection of pus in the orbit [1]. It comes from several sources including poly sinusitis. The narrow anatomical channels of the sinuses of the face with the neighboring structures explain the occurrence of ophthalmological and cerebral complications [2]. Through a clinical case, the current authors wanted to emphasize the infrequency of a bilateral intra-orbital abscess, to determine the place of Computed Tomography (CT) in etiological research and to emphasize therapeutic difficulties.

\section{Observation}

Mr. Gbe.T., a 65-year-old farmer, was received on $26^{\text {th }}$ June 2013 for headache and painful bilateral exophthalmos which intensified for about a week. He had a history of headache and fever that motivated his hospitalization in a health-center where an unspecified treatment was administered for an undefined period of time. The secondary appearance of pain and bilateral ocular protrusion prompted this consultation. In its antecedents, there is a purulent rhinorrhea developing since three months.

The ophthalmic examination permitted to note with the right eye a decline of visual acuity in an absence of luminous perception, a painful, axial, irreducible, non-pulsatile exophthalmos and without breath not measurable to the ophthalmometer of Hertel due to the importance of chemosis (Figure 1). Upper palpebral edema was noted as well as purulent secretions. The cornea was clear and transparent and the anterior cavity was calm and of normal depth. The pupil was dilated reactive with an opacified crystalline lens. The globe was stretched to digital palpation and the fundus of eye was inaccessible.

To the left eye, the visual acuity was uneasy to access; the biomicroscope examination was identical to that of the right eye apart from a myosis and an opalescent lens. The retina was perceived as blurred. The loco-regional examination revealed multiple decayed teeth. There was no evidence of lymphatic tachycardia or mandibular angulo.
The general condition was altered with hyperthermia at $38^{\circ} 9$ Celsius, a pulse at 110 beats per minute. It was infatuated with a Glasgow score at 13 . The blood analysis had revealed a leukocytosis with 21000 white blood cells. The CRP was $90.89 \mathrm{mg} / \mathrm{l}$. Fasting blood glucose and renal function were normal.

Cerebral orbito computed tomography showed a bilateral hypodense orbital image with its raised wall, hyperdense translating a collection (Figure 2) and a cerebral parietal right hypodense under dural limited by a raised wall, hyperdense (Figure 3 ).

The treatment used was a triple antibiotic treatment of Ceftriaxone iv $2 \mathrm{~g} \times 2$ /day, Metronidazole iv: $500 \mathrm{mg} \times 3$ /day and Gentamycin iv: $160 \mathrm{mg} /$ day). An anti-inflammatory treatment based on corticosteroid (Methylprednisolone iv: $80 \mathrm{mg} \times 3 /$ day) had been started on the fourth day of antibiotic therapy. Hydro-electrolyte rehydration and antipyretic therapy were introduced as well as oxygen therapy.

Changes in ocular symptoms (chemosis and palpebral edema) were observed, but hyperthermia persisted before being corrected after three weeks.

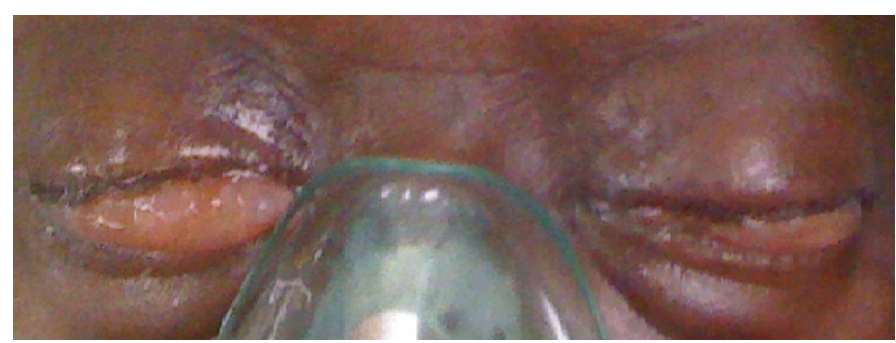

Figure 1. Palpebral edema and chemosis seen from the front

Correspondence to: Alamou Soulé, Ophthalmology Department, University Hospital HKM of Cotonou, 04 Po Box 0848 Cotonou, Benin, Tél: (00 229) 9713 69 86; E-mail : s_alamou@yahoo.fr

Key words: intra, orbital abscess, poly sinusitis, cerebral empyema, CT scan

Received: May 23, 2017; Accepted: June 16, 2017; Published: June 19, 2017 


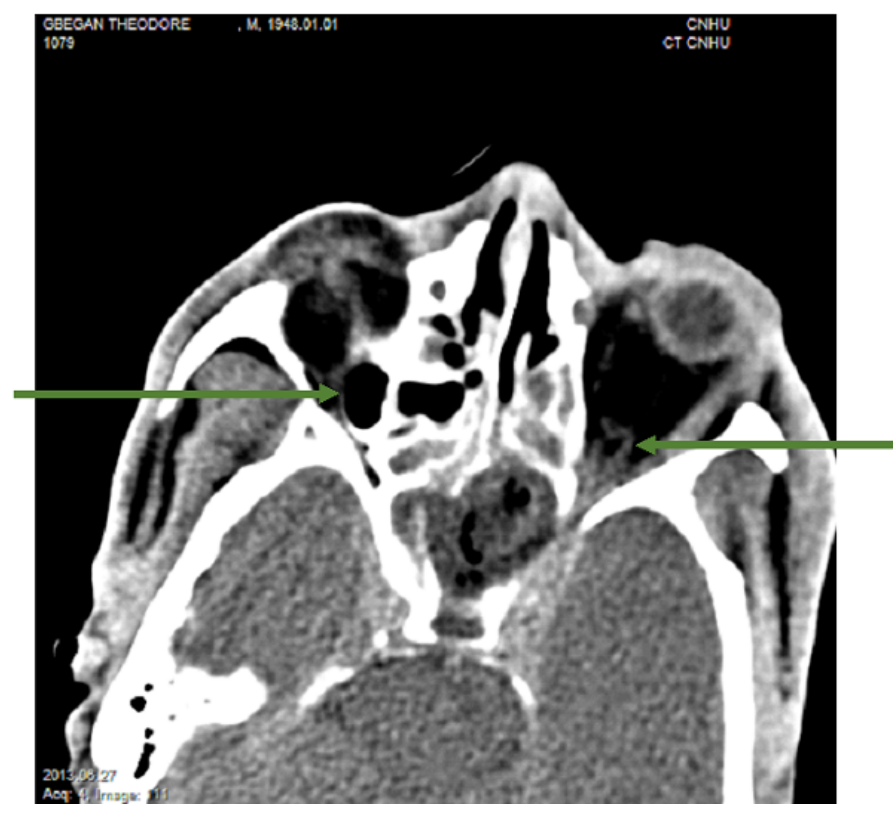

Figure 2. CT axial section showing:

- a right or left intra orbital abscess in the form of a hypodense image with its raised wall, hyperdense;

- a conglomeration of the ethmoidal cells and an abscess of the left sphenoidal sinus;

- involvement of the cavernous sinuses.

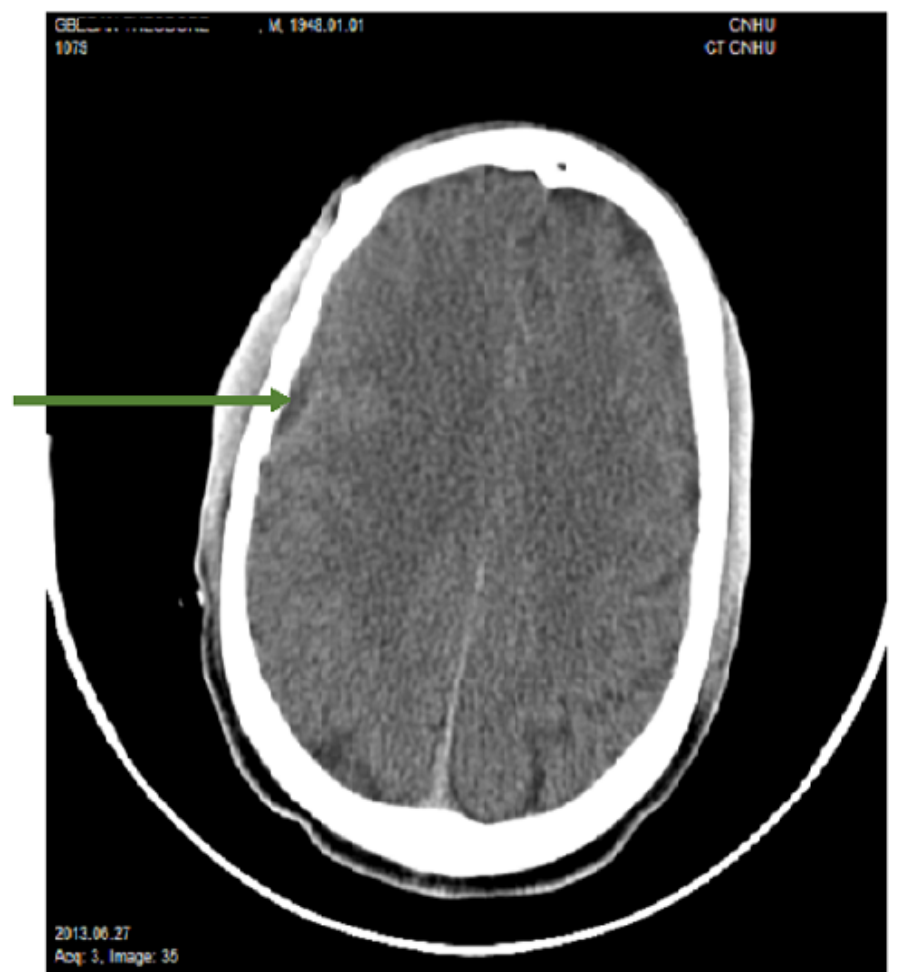

Figure 3. CT axial section showing a right hypodense parietal collection under dural constrained by a raised wall, hyperdense

\section{Discussion}

The occurrence of orbital complications is frequent during or after sinusitis [3]. Of the 82 patients admitted to the Mississippi Medical University Center between January 1, 1985 and December 31, 1999, Younis et al reported $52.44 \%$ of orbital complications and $47.66 \%$ intracranial complications [4]. According to Clayman, the occurrence of cranial and endocranial complications of nasosinus infections is difficult to assess. It would be $3.7 \%$ in 1991 [5]. For Adjibabi et al. in 2008, the occurrence of neuro-encephalic complications from ENT infection was a case per year [6].

In order to decline the occurrence, the endocranial complications encountered are brain abscesses, meningitis, subdural empyema, cavernous sinus thrombosis and sinus thrombosis lateral [5]. Orbital complications of nasosinus infections are often encountered in young male patients. The young age has been reported by some authors $[5,7]$. On the other hand, other authors have reported a bimodal distribution 6-15 years and 60-70 years [1]. The case presented here was a male at 65 years.

Diabetes, Acquired Immunodeficiency Syndrome (AIDS) and post-chemotherapy medullary aplasia have been associated as factors promoting the spread of sinus infection [5]. None of these factors were identified in the present study.

The clinical manifestations are variable and related to the anatomical seat of the infection.

Orbital complications of sinusitis are classified by Chandler according to the anatomo-clinical lesions and their localizations in 5 evolutionary stages:

- Grade I: pre-septal cellulitis or orbital inflammatory edema;

- Grade II: diffuse orbital cellulitis ;

- Grade III: subperiosteal abscess with visual loss and oculomotricity limitation;

- Grade IV: orbital abscess with significant visual drop and ophthalmoplegia ;

- Grade V: cavernous sinus thrombosis, blindness, contralateral ocular involvement, meningeal involvement with sepsis and alteration of consciousness) [8].

The case presented is similar to the last grade. Most authors reported unilateral complications [2,7]. The signs of cerebral abscess are not very specific, but the occurrence of a diffuse or two-stage headache is a warning sign, as well as the appearance of a focal neurological sign [5]. Clinical signs are represented by the triad composed of an infectious syndrome, an intracranial hypertension syndrome and neurological signs [5].

Endonasal endoscopy, a key examination, helps note the occurrence of pus in the middle meatus and take bacteriological samples.

The bacteria involved are staphylococcus, streptococcus, Haemophilus influenzae, fusobacteria, bacteroids [5, 7]. Among fungi, the fungus has often been found [5]. Still, cultures remain negative in about $20 \%$ of cases in the most recent series. This reflects the preoperative use of generally probabilistic intravenous antibiotic therapy which sterilizes the infectious focus [5], and/or the patient's self-medication. In the case presented, self-medication and the triple probabilistic antibiotic therapy initiated at the beginning of the hospitalization altered the bacteriological response thus depriving a definite diagnosis.

The diagnosis of orientation is based on the systematic realization of an injected cerebral tomodensitometry [9]. Indeed, the medical imaging is of major interest in the management of endocranial complications of ENT infections, allowing both the sinus and oto-mastoid origin 
to be determined, and to specify the ways for their spread (osteitis, Thrombophlebitis) and to make the assessment of extension (several intracranial complications may coexist) [10]. The sinusitis causing the cerebral complications are mainly frontal and sphenoidal [9].

Magnetic resonance imaging (MRI) is more sensitive than tomography (CT) in the evaluation of orbital involvement (soft tissue) but rarely used in emergencies and the orbital echocardiography is not very contributory in the study of the orbital apex according to Rajhi et al. [7].

In this observation, the orbito-cerebral scanner was used to determine the extent of sinusitis and the orbital and cerebral damage. The treatment of retro-septal cellulitis requires massive intravenous antibiotics with broad spectrum antibiotics covering aerobic and anaerobic bacteria in front of the emergency and then modulated according to the antibiogram. The duration of intravenous treatment is guided by the attainment of apyrexia and the reduction of symptoms [1]. It took 15 days for this patient similar to that of Ben et al., 16.5 days [7].

Surgery is advocated in the presence of ophthalmologic signs such as a decline in visual acuity, an afferent pupillary deficit (signing an optic neuropathy), major oculomotor disorders, an intra-orbital abscess or an aggravation of the clinical picture [1]. It is usually based on the realization of the purulent collection drainage. This can be done externally or by endoscopic by mean of metatotomy if it is the maxillary sinus, marsupialization of the sphenoid, repermeabilisation of the nasofrontal channel if it is the frontal and ethmoidectomy if it is the ethmoid [1]. It was not performed due to the amendment of the symptoms. Today the improvement is favorable when an early diagnosis and an adapted treatment have been undertaken. However, deaths are possible with a rate ranging from 5 to $21 \%[1,5,6,8,11]$.

\section{Conclusion}

The oculo-orbital and cerebral injuries due to infectious sinus origin remain serious because of their functional and vital prognosis.
Bilaterality, however, is rare. Medical imaging is very contributory. Early diagnosis, appropriate antibiotherapy and multidisciplinary collaboration (ENT, ophthalmologist, radiologist, neurologist, stomatologist and bacteriologist) are essential.

\section{References}

1. Mouriaux F, Rysanek B, Babin E, Cattoir V (2012) [Orbital cellulitis]. J Fr Ophtalmol 35: 52-57. [Crossref]

2. Soudant J, Lamas G. (1991) Complications ophtalmologiques en pathologie ORL Encycl Méd Chir (Éditions Médicales et Scientifiques Elsevier SAS Paris), Oto-RhinoLaryngologie, 20-920-A-10.

3. Duplessis D J. (2004) Current approach to sinusitis. CME 22: 240-245.

4. Younis RT, Lazar RH, Anand VK (2002) Intracranial complications of sinusitis: a 15year review of 39 cases. Ear Nose Throat J 81: 636-638, 640-642, 644. [Crossref]

5. Laurent G, Patrick M (1995) Complications crâniennes et endocrâniennes des infections nasosinusiennes. Encycl Méd Chir (Éditions Médicales et Scientifiques Elsevier SAS Paris), Oto-Rhino-Laryngologie, 20-445-A-10.

6. Adjibabi W, Avodé G, Biaou O, Lokossou Th, Avakoudjo F, et al. (2008) Les complications neuro-encéphaliques des infections ORL. La revue africaine d'ORL et de Chirurgie Cervico-Faciale; 6(1, 2, 3): 23-28.

7. Ben Amor M, Khalifa Z, Romdhane N, Zribi S, Ben Gamra O, et al. (2013) Orbital complications of sinusitis. J Fr Ophtalmol 36: 488-493. [Crossref]

8. Ailal F, Bousfiha A, Jouhadi Z, Bennani M, Abid A (2004) Orbital cellulitis in children: a retrospective study of 33. Med Trop (Mars) 64: 359-362. [Crossref]

9. Bayonne E, El Bakkouri W, Kania R, Sauvaget E, Tran Ba Huy P, Herman P. (2007) Complications crâniennes et endocrâniennes des infections naso sinusiennes. Encycl Méd Chir (Éditions Médicales et Scientifiques Elsevier SAS Paris), Oto-RhinoLaryngologie, 20-445-A-10, 9 p.

10. Riehm S, Veillon F (2011) Intracranial complications from ENT infections. $J$ Radiol 92: 995-1014. [Crossref]

11. Page C, Lehmann P, Jeanjean P, Strunski V, Legars D (2005) [Intra cranial abscess and empyemas from E.N.T. origin. Ann Otolaryngol Chir Cervicofac 122: 120-126. [Crossref]

Copyright: (C2017 Alamou S. This is an open-access article distributed under the terms of the Creative Commons Attribution License, which permits unrestricted use, distribution, and reproduction in any medium, provided the original author and source are credited. 